\title{
Relationship between iron deficiency and anemia in children younger than 4 years
}

\author{
Gisele Ane Bortolini, ${ }^{1}$ Márcia Regina Vitolo²
}

\begin{abstract}
Objective: To evaluate the prevalence of anemia, iron deficiency and iron deficiency anemia in a cohort of children.

Methods: A cohort study nested in a randomized field trial. Children were recruited at birth at the maternity unit of the only public hospital in the city of São Leopoldo, southern Brazil. This study assessed iron status (hemoglobin and serum ferritin) when children were 12-16 months old and later at the age of 3-4 years. Anemia was defined as hemoglobin concentration $<11.0 \mathrm{~g} / \mathrm{dL}$; iron deficiency as serum ferritin $<15.0 \mu \mathrm{g} / \mathrm{L}$; and iron deficiency anemia as hemoglobin concentration $<11.0 \mathrm{~g} / \mathrm{dL}$ with iron deficiency.

Results: At age 12-16 months, the overall prevalence of anemia, iron deficiency and iron deficiency anemia was $63.7,90.3$ and $58.8 \%$, respectively. The values for age group $3-4$ years were $38.1,16.1$ and $7.4 \%$, respectively. At age 12-16 months, $95 \%$ of anemia cases were associated with iron deficiency against only $19.3 \%$ of cases at age 3-4 years.

Conclusions: Iron deficiency was the main cause of anemia in the second year of life, but not at age 3-4 years. Thus, we point out that anemia in preschool children may have other causes and deserves careful assessment.
\end{abstract}

J Pediatr (Rio J). 2010;86(6):488-492: Infant, nutritional deficiency, preschool child.

\section{Introduction}

The World Health Organization (WHO), 1 in a recent publication, presented a comprehensive analysis of the worldwide prevalence of anemia between 1993 and 2005. Globally, anemia affects 1.62 billion people (95\%CI $1.50-$ 1.74 billion). Preschool children are the most affected, with prevalence of $47.4 \%$ (293 million). Furthermore, the prevalence of iron deficiency (ID) is estimated to be 2.5 times that of anemia. ${ }^{2}$
Data from the 2006 Brazilian Demographic and Health Survey, ${ }^{3}$ the first nationwide anemia prevalence survey in children, revealed that $20.9 \%$ of children aged zero to 59 months had anemia, i.e., approximately 3 million Brazilian children. The occurrence of anemia among children has been explored by several studies in Brazil over the last 20 years. A systematic review conducted in Brazil summarizes the results of 53 studies carried out between 1996 and

1. Mestre, Ciências Médicas. Programa de Pós Graduação em Ciências da Saúde, Universidade Federal de Ciências da Saúde de Porto Alegre (UFCSPA), Porto Alegre, RS, Brazil.

2. Pós-doutorado, Nutrição. Professora adjunta, Departamento de Nutrição, UFCSPA, Porto Alegre, RS, Brazil.

No conflicts of interest declared concerning the publication of this article.

Financial support: National Council for Scientific and Technological Development (CNPq), Brazil.

Suggested citation: Bortolini GA, Vitolo MR. Relationship between iron deficiency and anemia in children younger than 4 years. J Pediatr (Rio J). 2010;86(6):488-492.

Manuscript submitted Jul 07 2010, accepted for publication Sep 082010.

doi:10.2223/JPED.2039 
2007, at various scopes, and shows that the median data for anemia prevalence in this age group were 53\%, and the highest prevalence was found in children younger than 24 months. $^{4}$

In Brazil, there are no data on the national or regional prevalence of ID and few studies have assessed the prevalence of ID or ID anemia (IDA) in children. The results show an IDA prevalence of approximately 50\%. . $^{-8}$ However, the few studies that included other parameters to determine ID did not specify the different age groups. Therefore, the present study aimed to evaluate the prevalence of anemia, ID and IDA in a cohort of children followed from birth at ages 12-16 months and 3-4 years.

\section{Methods}

This is a cohort study nested in a randomized field trial of children recruited at birth at Hospital Centenário, the only hospital in the city of São Leopoldo, southern Brazil, only in the sectors providing care through the Brazilian public Unified Health System (SUS). Newborns eligible for the study had birth weight greater than 2,500 g and gestational age greater than 37 weeks. Mothers were invited to participate after being provided with detailed information on the study protocol, which included differences between intervention and control groups for implementation of a nutrition intervention program during the infant's first year of life. Sample size was calculated for a larger study, based on a frequency of exclusive breastfeeding up to 4 months old of $21.6 \%$ in the control group and an estimated $65 \%$ difference in the frequency of this practice between groups after intervention. Other parameters for this calculation were: $80 \%$ power and $95 \%$ confidence interval, which determined a sample size of 177 children in each group, totaling 354 children. Assuming $25 \%$ of losses, 500 motherchild pairs were recruited to reach the minimum sample size required. The initial study methodology has been described in detail elsewhere. ${ }^{9}$

The intervention program did not influence the prevalence of anemia among children, allowing them to be analyzed for this purpose regardless of to which group the child belonged. Children were assessed at age 12-16 months $(n=397)$ and later at age 3-4 years $(n=354)$. The sample for assessment of iron status was smaller due to losses caused by parents' refusal or because blood collection was not possible. Between the first and second assessments, no nutritional intervention was performed that could influence the nutritional status of children.

\section{Assessment of iron status}

All children evaluated at age 12-16 months and later at age 3-4 years were invited to undergo testing for assessment of iron status. Thus, whenever possible, fasting blood samples were drawn by venipuncture from each child. In the first evaluation, 369 samples of hemoglobin $(\mathrm{Hb})$ and 289 samples of serum ferritin (SF) were obtained. At 4 years of age, $\mathrm{Hb}$ was assessed in 354 children, SF in 321 children and C-reactive protein (CRP) in 318 children. $\mathrm{Hb}$ was measured with a Coulter counter, SF concentrations were analyzed by using a commercial ELISA kit, and CRP levels were measured by a high-sensitivity assay (detection limit $0.2 \mathrm{mg} / \mathrm{L}$ ) using the Behring Turbitimer System.

The outcome variables used were anemia, ID and IDA. Anemia was defined as $\mathrm{Hb}<11 \mathrm{~g} / \mathrm{dL}$, ID as ferritin $<15.0 \mu \mathrm{g} / \mathrm{L}$, and IDA as the concomitant presence of $\mathrm{Hb}<11 \mathrm{~g} / \mathrm{dL}$ and ferritin $<15.0 \mu \mathrm{g} / \mathrm{L}$. At 4 years of age, CRP concentration was used as a marker of inflammation, since inflammation-induced infection can increase ferritin concentrations regardless of iron status. Signs of infection or inflammation were defined as CRP concentration $\geq 6 \mathrm{mg} / \mathrm{L}$, and children below this cutoff value were excluded from the analysis. 2,10

\section{Statistical analyses}

All data were double entered on Epi-Info version 6.4 for subsequent validation. Data were analyzed using the Statistical Package for the Social Sciences (SPSS) version 13. Since this study is nested in a randomized field trial, ${ }^{8}$ the prevalence of anemia, ID and IDA was compared between intervention (I) and control (C) groups to demonstrate that the intervention program had no effect on iron status. Confirmation of this hypothesis allowed children from both groups to be analyzed together, thus increasing statistical power for this study. Prevalence did not differ between groups at age 12-16 months - anemia (I: 66\%; C: $60.1 \%$ ), ID (I: $89.5 \%$; C: $91 \%$ ), and IDA (I: $56.8 \%$; C: $52 \%)$ - and also did not differ at age 3-4 years - anemia (I: $41 \%$; C: $40.7 \%$ ), ID (I: $15.1 \%$; C: $17.1 \%$ ), and IDA (I: $7.9 \% ; C: 7.4 \%$ ).

Univariate analysis expresses the frequency of variables as proportion. Pearson's chi-square test was used for categorical variables, which evaluated the association between sex and the outcomes assessed. $P$ values $<0.05$ were considered to be statistically significant.

\section{Ethical considerations}

The research project was approved by the Research Ethics Committee of Universidade Federal do Rio Grande do Sul (UFRGS), Brazil. At the time of home interview, the parents or legal guardians received a consent form with detailed information on the procedures to be employed in the study, as well as the assurance of confidentiality of the information provided and the possibility of refusing to participate in the investigation. The collection was carried out only after the parents or legal guardians agreed to participate and signed the consent form. In both evaluations, all children were 
assessed (anthropometric evaluation and measurement of serum iron) and developmental examinations were performed. Children who were overweight, with short stature, malnutrition, dental problems or developmental problems were referred to primary care professionals for evaluation and treatment.

\section{Results}

The baseline socioeconomic characteristics of children's families revealed that $18.9 \%$ (75/397) of mothers were adolescents, $58.5 \%$ had less than 8 years of schooling, and $65.7 \%$ (257/391) had no paid occupation. Regarding family income, $71.9 \%$ of families had a monthly income $\leq$ three minimum salaries. Among children, 56.4\% were male. In the first evaluation of study outcomes, the mean age of the children was $12.95 \pm 1.15$ months (range: 11.84 to 16.25 months); in the second evaluation, the mean age of the children was $47.74 \pm 2.68$ months (range: 37.68 to 58.18 months).

At age 12-16 months, the prevalence of anemia, ID and IDA was 63.7, 90.3 and $58.8 \%$, respectively (Table 1 ). Among children with anemia, in this age group, 95\% (171/180) had ID. At age 3-4 years, the prevalence of anemia, ID and IDA was 38.1, 16.1 and $7.4 \%$, respectively. Among children with anemia, 19.3\% (22/114) had ID. Eighteen children $(5.7 \%)$ with elevated CRP concentration were excluded from the analysis. The results according to sex showed that the prevalence of ID and IDA was statistically higher among boys compared to girls only for age group 12-16 months (Table 2).

\section{Discussion}

The results of the present study showed that ID was associated with anemia in $95 \%$ of cases of children assessed at age 12-16 months, although at age 3-4 years this proportion was below $20 \%$. The $\mathrm{WHO}^{1,2}$ estimates that half of anemia cases are caused by ID and that the prevalence of ID is 2.5 times that of anemia. However, our study showed that this concept does not apply to children older than 2 years. Studies conducted with children in countries other than Brazil exhibited results similar to those presented in this article, with low serum retinol and folic acid levels being observed among children with anemia. ${ }^{11,12}$ Research conducted in Northeast Brazil with pregnant women

Table 1 - Prevalence* of anemia, iron deficiency, iron deficiency anemia and microcytosis in low-income children, according to age group

\begin{tabular}{lcccc}
\hline Age & Anemia (n) & ID (n) & IDA (n) & Microcytosis (n) \\
\hline 12 to 16 months & $63.7(235 / 369)$ & $90.3(261 / 289)$ & $58.8(170 / 289)$ & $51.1(187 / 366)$ \\
3 to 4 years & $38.1(114 / 299)$ & $16.1(48 / 298)$ & $7.4(22 / 298)$ & $32.8(98 / 299)$ \\
\hline
\end{tabular}

ID = iron deficiency; IDA = iron deficiency anemia

*\%.

Table 2 - Prevalence* of anemia, iron deficiency and iron deficiency anemia in children, according to age and sex

\begin{tabular}{|c|c|c|c|c|c|c|}
\hline Age/sex & Anemia (n) & $\mathbf{p}$ & ID (n) & $\mathbf{p}$ & IDA (n) & $\mathbf{p}$ \\
\hline \multicolumn{7}{|c|}{12 to 16 months } \\
\hline Male & $68.8(148)$ & 0.017 & $91.0(152)$ & 0.635 & $59.1(107)$ & 0.039 \\
\hline Female & $56.8(88)$ & $89.3(109)$ & $47.4(63)$ & & & \\
\hline \multicolumn{7}{|c|}{3 to 4 years } \\
\hline Male & $41.2(70)$ & 0.213 & $19.5(33)$ & 0.066 & $8.3(14)$ & 0.496 \\
\hline Female & $34.1(44)$ & $11.6(15)$ & $6.2(8)$ & & & \\
\hline
\end{tabular}

ID = iron deficiency (ferritin $<15 \mu \mathrm{g} / \mathrm{L}$ ); IDA = iron deficiency anemia (hemoglobin $<11 \mathrm{~g} / \mathrm{dL}$ and ferritin $<15 \mu \mathrm{g} / \mathrm{L}$ ); $\mathrm{p}=$ Pearson's chi-square test. 
revealed that ID was not the primary cause of anemia in this population. The prevalence of anemia was $56.6 \%$, and that of IDA was $10.7 \% .^{13}$

It is well established that deficiencies of vitamin B12 and folic acid are determinants of anemia in the absence of ID, but deficiencies of vitamin A, riboflavin and vitamin $C$ have also been described as possible causes of anemia, although the pathophysiological mechanisms involved are not yet fully understood. ${ }^{14,15}$ Two studies conducted with children showed deficiency of other micronutrients, such as vitamin B12, folic acid and vitamin A, after intervention with iron supplementation alone. ${ }^{16,17}$ However, in our study, anemia in preschool children does not seem to be associated with deficiency of vitamin B12 and folic acid due to the high prevalence of microcytosis observed. In Thai schoolchildren, hemoglobinopathies, suboptimal vitamin A status and age were the major predictors of $\mathrm{Hb}$ concentration. ${ }^{12}$

In Brazil, a recent nationwide study showed low frequency of sickle cell anemia in the population studied. ${ }^{3}$ It is also noteworthy that microcytosis is not present in sickle cell anemia, except in cases of co-inheritance of thalassemia. A study conducted in Rio Grande do Sul, the southernmost state of Brazil, analyzed blood samples from newborns screened by the National Newborn Screening Program and revealed that, of the 437,787 samples analyzed, 6,391 showed an abnormal $\mathrm{Hb}$ pattern. These included 48 cases $(0.01 \%)$ of sickle cell anemia, one neonate who was homozygous for $\beta$ thalassemia, 6,272 (1.4\%) newborns who were heterozygous for $\mathrm{Hb} \mathrm{S}, \mathrm{C}$, or $\mathrm{D}$, and $71(0.02 \%)$ neonates who were carriers for rare $\mathrm{Hb}$ variants. ${ }^{18}$ Thus, the low prevalence of sickle cell anemia and thalassemia observed nation and statewide could not justify the high prevalence of anemia without ID observed among preschoolers in this study.

Other non-nutritional factors implicated in the etiology of anemia include parasitic infections, such as malaria and hookworm disease. However, in Brazil, $99.5 \%$ of malaria cases occur in the North and Midwest of the country, ${ }^{19}$ and the presence of hookworm disease among preschoolers is associated with ID, a condition not found in our study. Thus, these factors could not serve as a basis for explaining the results described herein. Another aspect worth mentioning is the presence of anemia and microcytosis with adequate iron stores among low-income preschool children. Iron mobilization is reduced in the presence of vitamin $A$ deficiency. ${ }^{20}$ This may therefore be a potential hypothesis to explain the results observed in this study, since the 2006 Brazilian Demographic and Health Survey showed that $17.4 \%$ of Brazilian children younger than 5 years had deficient vitamin A concentrations. ${ }^{3}$ Another possible hypothesis may be related to the role of hepcidin, which is produced in the liver for iron metabolism. When iron stores are replete, this peptide inhibits the release of iron from the reticuloendothelial system to the circulation along with transferrin. If for some reason there is high hepcidin activity, this fact might explain why the stored iron would not be released to the circulation along with transferrin, resulting in high SF levels and low hematopoietic activity. 21,22

The absence of CRP measurement in the first evaluation of children could be a limitation of the study. CRP measurements aim to identify children with infections and to exclude these children from the analysis, since they may have increased ferritin levels as a result of infection and, thus, lead to a higher incidence of false-negative results for ID. Since ID prevalence in this age group (12-16 months) was $95 \%$, not excluding children with infections did not affect the conclusions of this study. For ethical reasons, all children who were diagnosed with anemia at age 12-16 months received a prescription for ferrous sulfate for a 3-month period. Since there was no follow-up of children after this period, the level of treatment adherence was not assessed. Therefore, since the interval between the first and second anemia assessment was approximately 2 years, we do not believe that low ID prevalence as a cause of anemia in children aged 3-4 years can be attributed to this factor.

Another aspect that may explain the low prevalence of ID among preschoolers is their ability to consume larger amounts of food - and, consequently, higher amounts of iron, especially of food made from wheat flour and corn flour, which are currently fortified - than when they were 12-16 months old.

We also highlight the higher prevalence of anemia and IDA among boys aged 12-16 months, which may be explained by the accelerated growth velocity during the first year of life, since growth velocity is higher in boys when compared to girls during this period. This process increases iron requirement, which is not often supplied by the diet due to the low bioavailability of dietary iron. At age 3-4 years, growth velocity is constant and much lower, thus no longer being an additional risk factor for IDA. ${ }^{23}$

The consequences of IDA are widely known, but anemia resulting from other nutritional deficiencies may also result in impaired health in children. Distinguishing between types of anemia resulting from causes other than ID represents a challenge to be overcome, as well as the consequences of unnecessary iron treatment. Data from this study highlight the importance of targeting interventions to children in the first year of life, before they become anemic or iron deficient, through the promotion of breastfeeding and adequate introduction of complementary foods. ${ }^{24}$ After 6 months of life, the Brazilian Society of Pediatrics and the Brazilian Ministry of Health recommend prophylactic iron supplementation up to 2 years of age. 25,26 However, prevention and control of nutritional anemia probably require the use of multiple micronutrients, since children with insufficient dietary intake of iron are likely to show inadequate intake of other micronutrients necessary for their proper growth. A recent review 27 and meta-analysis 28 
assessed the effects of individual and multiple micronutrient supplements on the nutritional status of populations in different settings and showed better results with the use of multiple micronutrient supplements.

\section{Conclusion}

The results showed that ID, considered the most prevalent nutritional deficiency in the world, is the leading cause of anemia in children aged 12-16 months, but not at age 3-4 years. Therefore, it does not seem appropriate to use the prevalence of anemia as a proxy for IDA, regardless of age. Thus, further studies are warranted to explore the causes of low $\mathrm{Hb}$ levels in children with adequate iron stores and to elucidate other causes of anemia in children older than 2 years.

\section{References}

1. World Health Organization. Worldwide prevalence of anaemia 1993-2005: WHO global database on anemia. Edited by Benoist B, McLea E, Egli I, Cogswell M. Geneva: WHO, 2008.

2. World Health Organization. Iron deficiency anaemia: assessment, prevention, and control. A guide for programme managers. Geneva: WHO, 2001.

3. Brasil. Ministério da Saúde, Centro Brasileiro de Análise e Planejamento. Pesquisa Nacional de Demografia e Saúde da Criança e da Mulher - PNDS 2006: dimensões do processo reprodutivo e da saúde da criança. Brasília: Ministério da Saúde, 2009.

4. Jordão RE, Bernardi JL, Barros Filho Ade A. Prevalência de anemia ferropriva no Brasil: uma revisão sistemática. Rev Paul Pediatr. 2009;27:90-8.

5. Hadler MC, Juliano Y, Sigulem DM. Anemia do lactente: etiologia e prevalência. J Pediatr (Rio J). 2002;78:321-6.

6. Almeida CA, Ricco RG, Ciampo LA, Souza AM, Pinho AP, Oliveira JE. Fatores associados a anemia por deficiência de ferro em crianças pré-escolares brasileiras. J Pediatr (Rio J). 2004;80:229-34.

7. Biscegli TS, Correa CE, Romera J, Candido AB. Estado nutricional e carência de ferro em crianças freqüentadoras de creche antes e 15 meses após intervenção nutricional. Rev Paul Pediatr. 2009;27:289-95.

8. Carvalho AG, de Lira PI, de Fátima Alcântara Barros M, Aléssio ML, de Carvalho Lima M, Carbonneau MA, et al. Diagnosis of iron deficiency anemia in children of Northeast Brazil. Rev Saude Publica. 2010;44:513-9.

9. Vitolo MR, Bortolini GA, Feldens CA, Drachler Mde L. Impactos da implementação dos dez passos da alimentação saudável para crianças: ensaio de campo randomizado. Cad Saude Publica. 2005;21:1448-57.

10. Abraham K, Müller C, Grüters A, Wahn U, Schweigert FJ. Minimal inflammation, acute phase response and avoidance of misclassification of vitamin A and iron status in infants - importance of a high-sensitivity C-reactive protein (CRP) assay. Int J Vitam Nutr Res. 2003;73:423-30.

11. Villalpando S, Pérez-Expósito AB, Shamah-Levy T, Rivera JA. Distribution of anemia associated with micronutrient deficiencies other than iron in a probabilistic sample of Mexican children. Ann Nutr Metab. 2006;50:506-11.

12. Thurlow RA, Winichagoon $P$, Green $T$, Wasantwisut $E$, Pongcharoen $\mathrm{T}$, Bailey KB, et al. Only a small proportion of anemia in northeast Thai schoolchildren is associated with iron deficiency. Am J Clin Nutr. 2005;82:380-7.
13. Bresani CC, Souza AI, Batista Filho M, Figueiroa JN. Anemia and iron deficiency in pregnant women: disagreements among the results of cross-sectional study. Rev Bras Saude Mater Infant. 2007;7:15S-21S.

14. Fishman SM, Christian P, West KP. The role of vitamins in the prevention and control of anaemia. Public Health Nutr. 2000;3:125-50.

15. Jamil KM, Rahman AS, Bardhan PK, Khan AI, Chowdhury F, Sarker SA, et al. Micronutrients and anaemia. J Health Popol Nutr. 2008;26:340-55.

16. Hadler MC, Sigulem DM, Alves Mde F, Torres VM. Treatment and prevention of anemia with ferrous sulfate plus folic acid in children attending daycare centers in Goiânia, Goiás State, Brazil: a randomized controlled trial. Cad Saude Publica. 2008;24 Suppl 2:S259-71.

17. Allen LH, Rosado JL, Casterline JE, Lopez P, Munoz E, Garcia OP, et al. Lack of hemoglobin response to iron supplementation in anemic Mexican preschoolers with multiple micronutrient deficiencies. Am J Clin Nutr. 2000;71:1485-94.

18. Wagner SC, de Castro SM, Gonzalez TP, Santin AN, Zaleski CF, Azevedo LA, et al. Neonatal screening for hemoglobinopathies: results of a public health system in South Brazil. Genet Test Mol Biomarkers. 2010;14:565-9.

19. Brasil. Ministério da Saúde. Secretaria de Vigilância em Saúde. Guia de vigilância epidemiológica. Brasília: Ministério da Saúde, 2005. www.saude.gov.br/svs.

20. Roodenburg AJ, West CE, Beguin Y, van Dijk JE, van Eijk HG, Marx $\mathrm{JJ}$, et al. Indicators of erythrocyte formation and degradation in rats with either vitamin A or iron deficiency. J Nutr Biochem. 2000;11:223-30.

21. Dallalio G, Fleury T, Means RT. Serum hepcidin clinical specimens. $\mathrm{Br}$ J Haematol 2003;122:996-1000.

22. Ganz T. Hepcidin, a key regulator of iron metabolism and mediator of anemia of inflammation. Blood. 2003;102:783-8.

23. Wieringa FT, Berger J, Dijkhuizen MA, Hidayat A, Ninh NX, Utomo B, et al. Sex differences in prevalence of anaemia and iron deficiency in infancy in a large multi-country trial in South-East Asia. Br J Nutr. 2007;98:1070-6.

24. Brasil. Ministério da Saúde. Secretaria de Atenção à Saúde. Departamento de Atenção Básica. Dez passos para uma alimentação saudável: guia alimentar para crianças menores de dois anos: um guia para o profissional da saúde na atenção básica. Brasília: Ministério da Saúde, 2010.

25. Sociedade Brasileira de Pediatria (SBP). Departamento de Nutrologia. Manual de orientação: alimentação do lactante, alimentação do pré-escolar, alimentação do escolar, alimentação do adolescente e alimentação na escola. São Paulo: SBP, 2006.

26. Brasil. Ministério da Saúde. Secretaria de Atenção à Saúde. Departamento de Atenção Básica. Manual Operacional: programa nacional de suplementação de ferro. Brasília: Ministério da Saúde, 2005. www.saude.gov.br/nutricao.

27. Fishman SM, Christian P, West KP. The role of vitamins in the prevention and control of anaemia. Public Health Nutr. 2000;3:125-50.

28. Allen LH, Peerson JM, Olney DK. Provision of multiple rather than two or fewer micronutrients more effectively improves growth and other outcomes in micronutrient-deficient children and adults. J Nutr. 2009;139:1022-30.

Correspondence:

Gisele Ane Bortolini

QRSW 06, Bloco B7, ap. 105 - Setor Sudoeste

CEP 70675-627 - Brasília, DF - Brazil

E-mail: giselebortolini@hotmail.com 